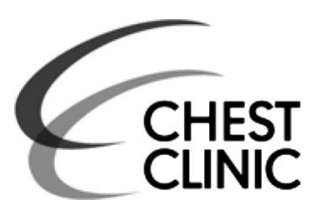

'Department of Respiratory Medicine, Royal Bournemouth \& Christchurch Hospitals NHS Foundation Trust,

Bournemouth, UK ${ }^{2}$ Department of Respiratory Medicine, Royal Bournemouth Hospital, Bournemouth, UK

\section{Correspondence to} Dr Heena Mistry, Respiratory Medicine, Royal Bournemouth \& Christchurch Hospitals NHS Foundation Trust, Bournemouth BH7 7DW, UK; hmmist25@gmail.com

HM and NR are joint first authors.

Received 15 February 2015 Accepted 16 March 2015

Published Online First 2 April 2015
CrossMark

To cite: Mistry $\mathrm{H}$,

Ranaweera N, Laws DE.

Thorax 2015;70:913-914.

\title{
Intrathoracic extramedullary haemopoiesis in a patient with hereditary spherocytosis
}

\author{
Heena Mistry, ${ }^{1}$ Nilushi Ranaweera, ${ }^{1}$ Diane E Laws ${ }^{1,2}$
}

\section{HISTORY}

A 63-year-old Thai man with hereditary spherocytosis presented with pruritus of his legs and subsequently found to have a raised serum ferritin of $1638 \mu \mathrm{g} / \mathrm{L}$. He had previously not required transfusional support. A referral was made to the gastroenterologists for investigation of iron overload. The HFE gene was not detected, thereby excluding hereditary haemochromatosis.

A T2* MRI scan was performed to identify areas of high iron load as part of the transfusion programme at the Royal Bournemouth Hospital for patients with myelodysplastic syndromes. This showed a large mass in the posterior right chest and a $3 \mathrm{~cm} \times 4 \mathrm{~cm}$ mass in the inferomedial left chest (figures 1 and 2).

Consequently, a CT staging scan of the thorax and abdomen identified a $12.4 \mathrm{~cm} \times 8.6 \mathrm{~cm} \times 9.7 \mathrm{~cm}$ heterogeneous pleurally based mass posteriorly at the right lung base, which was extraparenchymal and compressing the right lower lobe (figure 3). In addition, other multiple pleural-based soft tissue masses were present.

Ultrasound-guided pleural biopsies of the right lung mass were taken and histology of the samples revealed cellular haemopoietic tissue. Interestingly, this finding, along with a history of hereditary spherocytosis, was suggestive of these masses representing intrathoracic extramedullary haemopoietic tumours.

Currently, the patient remains well with some mild dyspnoea. He was referred to a specialist centre for further advice regarding the management

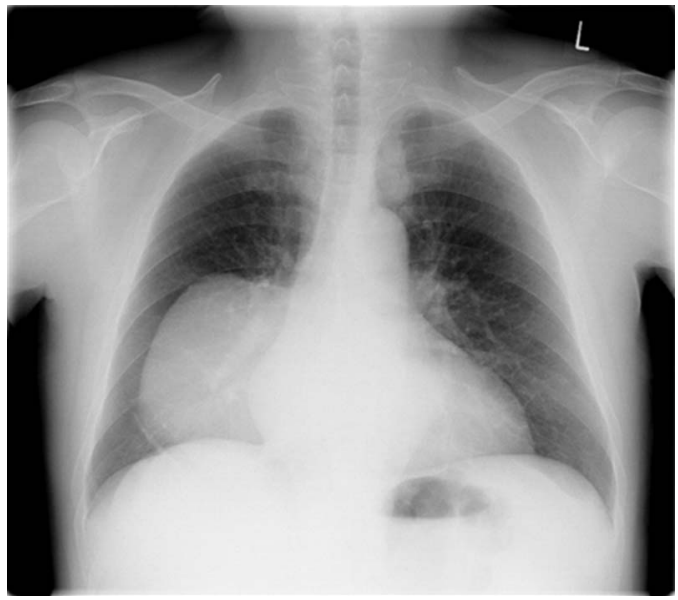

Figure 1 Chest radiograph showing a large, well-circumscribed mass-like lesion in the right hemithorax.

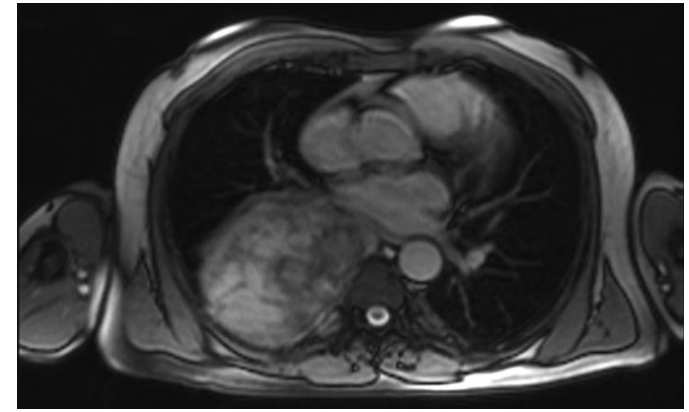

Figure 2 A T2* cardiac MRI scan showing a $10 \mathrm{~cm} \times 11$ $\mathrm{cm} \times 10 \mathrm{~cm}$ mass in the posterior right hemithorax.

of these intrathoracic haemopoietic lesions, as well as elucidating the link between iron overload and hereditary spherocytosis. He was advised to commence on the iron chelating agent deferasirox and a subsequent ferriscan showed a vast improvement.

\section{DISCUSSION}

Hereditary spherocytosis is the most common cause of haemolytic anaemia, resulting from defects in the red cell membrane. This is due to defective bone marrow erythropoiesis. As a consequence, extramedullary haematopoiesis can occur as a compensatory mechanism due to the resulting chronic anaemic state. ${ }^{1}$ Common sites involved include liver, spleen and lymph nodes. ${ }^{2}$ Extramedullary haemopoietic tumours rarely occur intrathoracically. ${ }^{2}$ Large

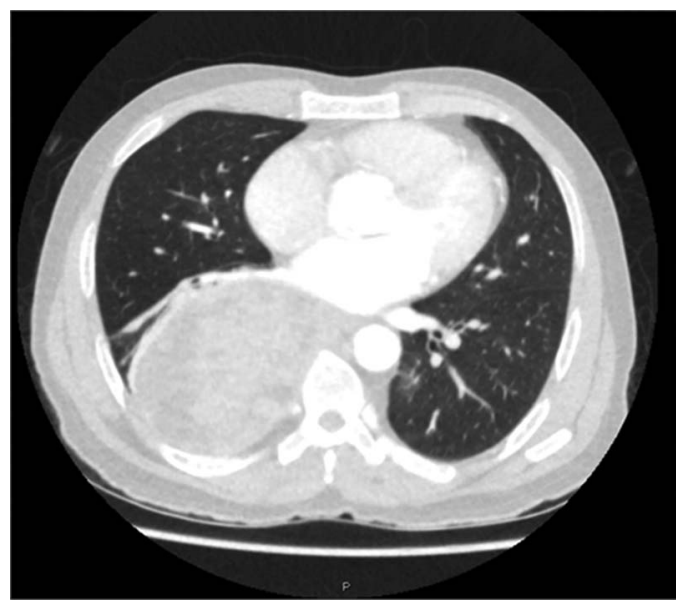

Figure 3 A CT thorax and abdomen staging scan showing a $12.4 \mathrm{~cm} \times 8.6 \mathrm{~cm} \times 9.7 \mathrm{~cm}$ heterogeneous pleurally based mass posteriorly at the right lung base. This mass is extraparenchymal and compressing the right lower lobe. 


\section{Chest clinic}

mass-like lesions are less commonly found as usually these tumours present microscopically. ${ }^{3}$ This phenomenon can also be seen in myeloproliferative blood disorders. ${ }^{2}$ Other rarer thoracic consequences include pleural effusions, haemothorax, respiratory failure and cord compression. ${ }^{3}$

Acknowledgements We acknowledge the help of Dr Sally Killick, Consultant Haematologist at Royal Bournemouth Hospital, and Dr Jo Howard, Consultant Haematologist at Guy's \& St Thomas' Hospital, in their ongoing expert care of the patient concerned. We are also grateful to the patient for providing consent for the publication of this article.

Contributors DEL initially reviewed the patient and conceived the idea. HM and NR wrote the manuscript and are guarantors of the overall content. All authors approved the final manuscript.
Competing interests None.

Patient consent Obtained.

Provenance and peer review Not commissioned; externally peer reviewed.

\section{REFERENCES}

1 Bastion Y, Coiffier B, Felman P, et al. Massive mediastinal extramedullary haematopoiesis in hereditary spherocytosis: A case report. Am J. Hematol 1990;35:263-5.

2 Gogia P, Goel R, Nayar S. Extramedullary paraspinal hematopoiesis in hereditary spherocytosis. Ann Thorac Med 2008;3:64-6.

3 Agarwala R. Extramedullary hematopoiesis. App/ Radiol 2006;35. http://www. appliedradiology.com/lssues/2006/04/Cases/Extramedullary-hematopoiesis-(EMH).aspx 